\title{
The Relationship between Loan Portfolio Size and Risk Diversification for Commercial Bank
}

\author{
Y. ZHANG, S. ZHOU, B. S. SHI \\ School of Economics and Management, Southwest Jiaotong University, Chengdu, China
}

\begin{abstract}
The risk-adjusted return on capital (RAROC) which is one of the most important indicators in commercial bank is used to study the risk diversification effectiveness of loan portfolio size under the economic capital constraints. About $68.09 \%$ s' average risk of loan portfolio can eliminated by 10 sub-branches and $74.79 \%$ s' average risk of loan portfolio can eliminated by 19 sub-branches which can consider as the proper size of portfolio. Furthermore, the similarities and differences between loan portfolio and stock investment are analyzed.
\end{abstract}

KEYWORD: Loan portfolio; Risk diversification; Comprehensive profit; Internal management

\section{INTRODUCTION}

As the bank's greatest resource, loan is scarce and limited. The inherent demand of economical development for capital is far greater than supply, which leads to the tight correlation between comprehensive profit of bank and loan distributing. Therefore, it is important to make good use of the loan resources and establish the optimal model of loan portfolio.

The optimal model of mean-variance is widely accepted as the basis of modern portfolio theory. An effective complement of studying the systematic risk and unsystematic risk of portfolio yield has been extended the theory. More recently, many researches about loan management were proposed and analyzed based on portfolio theory. As pointed out in Hass et al. (2011), bank ownership, bank size and legal creditor protection were important determinants of the composition of bank's loan portfolio. Portfolio is one of the efficient methods to reduce investment risk. As shown by Wu and Wei (1998), the proper size of portfolio for Shanghai stock market was 21-30 stocks through making 30 equally weighted portfolios. Yang and Zhang (2005) made an empirical analysis on the relationship between the size of portfolio and the investment risk by using the 36 stock's monthly return data selected from Shanghai 50 Index. After dividing the eleven years' data (19952005) in Chinese stock market into three sub sample periods, Chen et al. (2008) discussed the relationship between the increasing portfolio sizes and the diversification of unsystematic risk. Moreover, a well diversified portfolio can not only reduce the variance, but also earn an incremental return by a rebalanced portfolio of assets.

Those researches mainly focused on the stock market, and there were little works on the relationship between the loan portfolio size and risk diversification. The main goal of this paper is to use the risk-adjusted return on capital (RAROC) which is one of the most important indicators in commercial bank to study the risk diversification effectiveness of loan portfolio size. Our main concerns are the operation organizations of state-owned bank, and RAROC of the comprehensive profit on loan is the major consideration.

The paper is organized as follows: Section 2 introduces the concept of RAROC and gives the practical RAROC measurement method. The process to obtain the risk diversification effectiveness of loan portfolio size is designed in Section 3, and the numerical example based on the data from commercial bank is given in Section 4. Finally, the paper is briefly concluded in Section 5.

\section{RAROC OF THE COMPREHENSIVE PROFIT ON LOAN}

RAROC was developed by Bankers Trust New York Corporation in the late 1970s and was applied as a risk-based profitability measurement index to assist banks and financial institutions. Since RAROC measurement system takes return, risk and capital into this index, it not only reflects the bank's expected return more accurately and objectively, but also reveals the operating efficiency of economic capital. 
This paper uses the comprehensive profit including the profits from loan, deposit and intermediary business instead of the loan profit, and the provision set aside by bank instead of expected loss. Therefore we have the following definitions.

Definition 1. The RAROC of the comprehensive profit on loan can be written as

$$
\text { RAROC }=\frac{\text { Comprehenisve profiton loan }}{\text { Economicapital }}
$$

where Comprehensive profit on loan= (Comprehensive income - Comprehensive cost - Business tax - Provision $) \times(1-$ Corporate income tax), Comprehensive income $=$ Loan income + Deposit income + Intermediary business income, Comprehensive cost $=$ Loan capital cost + Deposit capital cost.

RAROC is the ratio of net profit eliminated risk factors from specific asset or business unit to economic capital. In the other hand, the economic capital determined by the risk of credit asset is used to offset the unexpected loss. Therefore, the RAROC measurement model based on the comprehensive profit on loan is beneficial to not only establish the capital constraints system and incentive system internally, but also reflect the profitability and capital return of commercial bank.

Definition 2. The proportionality coefficient of economic capital is designed according to the internal management of economic capital in Chinese commercial banks as the following form:

$$
\text { Proportioal it ycoefficien }=\frac{\text { Economicapital }}{\text { Balanceof loan }}
$$

This coefficient means the unexpected loss per unit loan, and can reflect the use efficiency of the loan. Usually, the smaller the value is the better. For example, if the value of this coefficient is 0.05 , it means that 500 thousands economic capitals are needed to protect against the unexpected loss in each 10 million loans.

\section{LOAN PORTFOLIO SIZE AND RISK DIVERSIFICATION}

The internal assessment of most Chinese commercial banks still focuses on the loan scale, and the operation sub-branches pursuit the business scale and short-term gains. With the operation organizations of a state-owned bank as research objects, this paper will study the risk diversification effectiveness of loan portfolio management on the meso level.

\subsection{Instruction of sample data}

According to the definition 1, we can obtain the necessary RAROC dataset of the comprehensive profit on loan for research based on the collecting, inducting and calculating for the basic data.

In order to make the dataset to be comparable, we adopt the annualized current deposit transfer revenues or interest payments and annualized loan interest income or loan capital cost as the basis of measurement. Meanwhile, the formulas introduced in definition 1 do not consider the depreciation of fixed assets, operating cost including labor cost and the other taxes except business tax and income tax.

\subsection{Loan portfolio}

Let $R_{i t}$ be the $i$ th $(i=1,2, \ldots, 24)$ sub-branch's RAROC of the comprehensive profit on loan in the $t$ th year, and $R_{t}$ be the $i$ th sub-branch's average annualized RAROC which can be calculated by arithmetical method as follows:

$$
R_{i}=\sum_{t} R_{i t} / T
$$

where $T$ is the sample period, let $T=5$. Because of the strict audit work before lending, the loan income is relatively safe and stable, and its volatility is much smaller than volatility of the stock market.

And the standard deviation $\sigma_{i}$ of these subbranches' RAROC can be obtained as

$$
\sigma_{i}=\sqrt{\sum_{t}\left(R_{i t}-R_{i}\right)^{2} /(T-1)}
$$

Based on the sample dataset from 24 subbranches, we can calculate the RAROC and its standard deviation of loan portfolio denoted by $R_{P}$ and $\sigma_{P}$ through the following theorem.

Theorem 1. Let $w_{i}$ and $\varphi_{i}$ be the weight and latest year's proportionality coefficient of $i$ th sub-branch, respectively. $\quad w=\left(w_{1}, w_{2}, \ldots, w_{n}\right)^{\mathrm{T}}, \quad \varphi=\left(\varphi_{1}, \varphi_{2}, \ldots, \varphi_{n}\right)^{\mathrm{T}}$. Then the expected RAROC and its standard deviation of loan portfolio can be given by

$$
R_{P}=\frac{1}{w^{T} \varphi} \sum_{i} w_{i} \varphi_{i} R_{i}
$$

$$
\sigma_{P}=\frac{1}{w^{T} \varphi} \sqrt{\sum_{i, j} \varphi_{i} \varphi_{j} w_{i} w_{j} \sigma_{i j}}=\frac{1}{w^{T} \varphi} \sqrt{\sum_{i, j} \varphi_{i} \varphi_{j} w_{i} w_{j} \rho_{i j} \sigma_{i} \sigma_{j}}
$$

where $\sigma_{i j}$ is the covariance of two sub-branches' RAROC, and $\rho_{i j}$ is the correlation coefficient.

Proof. Assume that $D_{i}, C_{i}$ and $P_{i}$ are the balance of loan, economic capital and comprehensive profit of $i$ th sub-branch, respectively. We have $P_{i}=C_{i} R_{i}$ $=D w_{i} \varphi_{i} R_{i}, D$ is the total balance of loan. Then, RAROC of loan portfolio can be obtained as follows

$$
R_{P}=\frac{P}{C}=\frac{\sum_{i} P_{i}}{\sum_{i} C_{i}}=\frac{\sum_{i} D w_{i} \varphi_{i} R_{i}}{\sum_{i} D w_{i} \varphi_{i}}=\frac{1}{w^{T} \varphi} \sum_{i} w_{i} \varphi_{i} R_{i}
$$


And it is obvious that the standard deviation is

$$
\sigma_{P}=\frac{1}{w^{T} \varphi} \sqrt{\sum_{i, j} \varphi_{i} \varphi_{j} w_{i} w_{j} \sigma_{i j}}=\frac{1}{w^{T} \varphi} \sqrt{\sum_{i, j} \varphi_{i} \varphi_{j} w_{i} w_{j} \rho_{i j} \sigma_{i} \sigma_{j}} .
$$

Because of the economic capital constraint, the weights of loan have been modified by $\varphi_{i}$. This paper mainly study the relationship between the risk diversification and loan portfolio, it is reasonable to assume the weights to be equal.

\section{HISTORICAL SIMULATION ANALYSIS}

\subsection{Simulation design}

We start our simulation by picking the sample branch randomly without replacement, and can construct 24 loan portfolios based on the number of sample branch. On a step-by-step basis, the following simulation design enables us to obtain the expected RAROC and standard deviation of loan portfolio for risk diversification analysis:

(1) We select the first branch $S_{1}$ randomly from 24 sub-branches of a commercial bank in a provincial city and take the first average RAROC $R_{1}$ and standard deviation $\sigma_{1}$.

(2) We select the second branch $S_{2}$ randomly from the remaining 23 sub-branches, and establish a loan portfolio of two sample objects with equal weights. Then the related indexes of loan portfolio can be obtained.

(3) We select the third branch $S_{3}$ randomly from the remaining 22 sub-branches, and establish a three objects loan portfolio with equal weights. And we also can calculate the related indexes of this loan portfolio by theorem 1 .

(4) According to this step-by-step basis, we will have 24 loan portfolios from one sample sub-branch to 24 sample sub-branches, respectively. RAROCs and standard deviations with different loan portfolio sizes can be given with the same manipulations.

(5) Repeat the above four steps 30 times and we will obtain the average RAROCs and standard deviations of different loan portfolio sizes calculated by 30 sets of data.

Then the fifth step can avoid the defect of the abnormal fluctuations of RAROC and standard deviations due to one random sampling, and the final average RAROCs and standard deviations calculated in step 5 are more appropriate.

\subsection{Simulation results analysis}

Because we simulate 30 times of random sampling for loan portfolio, it weakens the effects of the instability caused by a single sub-branch's data. Then the probability of abnormal fluctuations of the RAROC and standard deviation will be reduced. Table 1 and Table 2 show the simulation results of the average RAROCs and standard deviations under the different loan portfolio sizes, respectively.

Table 1. The average RAROC with different loan portfolio sizes $(\%)$.

\begin{tabular}{lcccccc}
\hline Size & 1 & 2 & 3 & 4 & 5 & 6 \\
RAROC & 18.40 & 19.31 & 19.35 & 19.98 & 19.53 & 19.32 \\
\hline Size & 7 & 8 & 9 & 10 & 11 & 12 \\
RAROC & 19.59 & 19.67 & 19.56 & 19.54 & 19.32 & 19.24 \\
\hline Size & 13 & 14 & 15 & 16 & 17 & 18 \\
RAROC & 19.35 & 19.35 & 19.27 & 19.31 & 19.35 & 19.52 \\
\hline Size & 19 & 20 & 21 & 22 & 23 & 24 \\
RAROC & 19.55 & 19.63 & 19.56 & 19.61 & 19.75 & 19.59 \\
\hline
\end{tabular}

Table 2. The average standard deviation with different loan portfolio sizes $(\%)$.

\begin{tabular}{lcccccl}
\hline Size & 1 & 2 & 3 & 4 & 5 & 6 \\
$\sigma$ & 9.40 & 6.91 & 5.82 & 5.36 & 4.80 & 4.36 \\
\hline Size & 7 & 8 & 9 & 10 & 11 & 12 \\
$\sigma$ & 4.15 & 3.64 & 3.44 & 3.00 & 2.92 & 2.79 \\
\hline Size & 13 & 14 & 15 & 16 & 17 & 18 \\
$\sigma$ & 2.75 & 2.59 & 2.37 & 2.36 & 2.43 & 2.42 \\
\hline Size & 19 & 20 & 21 & 22 & 23 & 24 \\
$\sigma$ & 2.36 & 2.22 & 2.12 & 2.09 & 2.16 & 2.00 \\
\hline
\end{tabular}

The results given in Table 1 confirm the stability of RAROC of the comprehensive profit on loan during the sample period. When the number of sample sub-branches is more than 2, the RAROCs under different loan portfolio sizes fluctuate inside narrower interval relatively. The difference between the highest and the lowest values of RAROC is just $0.71 \%$.

There may exist large difference between the volatilities of some sample sub-branches because of their different business develop situations and business objects. After several random sampling in our simulation process, Table 2 shows the risk diversification effectiveness of loan portfolio size based on the proportionality coefficient of economic capital. The average volatility of loan portfolio declines when the number of the sub-braches in the portfolio increases. Then we obtain the following figures.

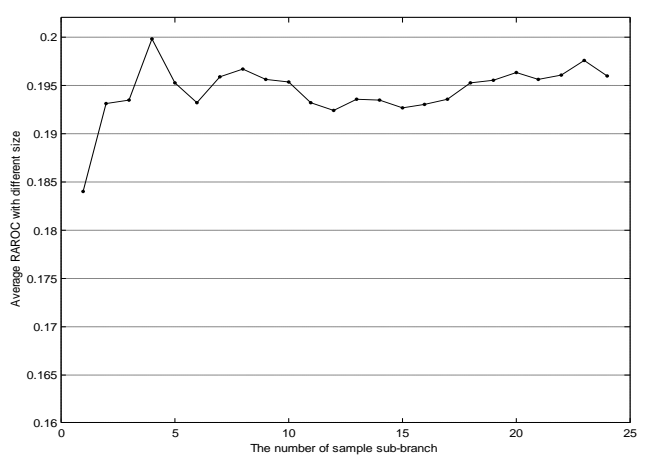

Figure 1. The relationship between average RAROC and loan portfolio size. 


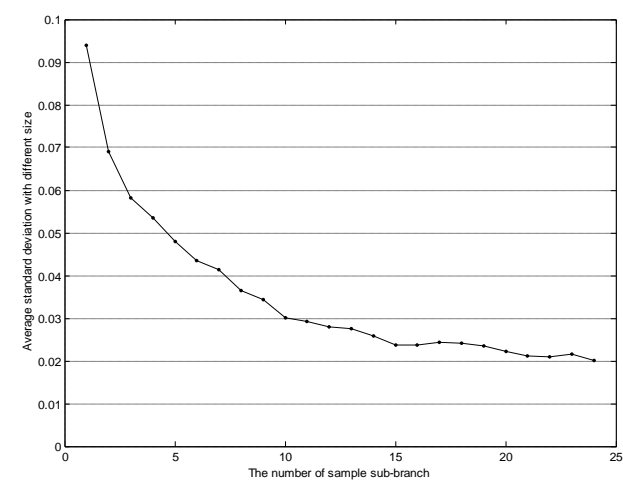

Figure 2. The relationship between risk diversification and loan portfolio size.

As shown in Figure 2, the number of the subbraches in the portfolio increases from 1 to 10 , while the average risk of loan portfolio declines with a form of a rapidly decreasing. About $68.09 \%$ 's average risk can be eliminated by the loan portfolio with $10 \mathrm{sub}$ branches. But with the number of sub-branches keeping on rising, the risk diversifying ability will show the marginal effect of decreasing trend which performs in Figure 2 with declining rather slowly. If the number of the sub-branches is between 11 and 24 , the corresponding risk will be in a narrow range. Furthermore, the residual risk is reduced very small if we consider more than 15 sub-branches. Then it can be said that the proper size of loan portfolio for subbranches will be 15, and about $74.79 \%$ 's risk is eliminated by this loan portfolio.

According to the portfolio theory, the unsystematic risk can be reduced by assembling a portfolio with significant, and the rest variance is the systematic risk which is impossible to be diversified by the portfolio. The numerical results show that the unsystematic risk and systematic risk ratio is about $8: 2$ in our simulation.

\subsection{Simulation results analysis}

Combined with the previous researches, the risk diversification is quite different between the portfolio size of securities and loans. First of all, their essential attribute of assets are different. There exists the benchmark lending rate, so the RAROC of the comprehensive profit on loan is stable relatively. The prices of securities will be highly volatile. Secondly, the research objects are different. Existing literatures studied the theory of diversifying investment risk through portfolio selected from the stock market. And this paper concerns the sub-branches of state-owned bank in a provincial city, and the portfolio is established from the view of operation organizations instead of borrowing enterprises. Finally, the systematic risk is highly correlated with the scale, strength, operation ability and risk control ability of the commercial banks. The influence of systematic risk on loan is much smaller than the securities in stock market.

\section{CONCLUSIONS}

The relationship between risk diversification and loan portfolio size is studied based on the practical data from the operation organizations of state-owned bank in this paper. We simulate 30 times of random sampling for loan portfolio, and the results show that the loan portfolio with 10 sub-branches can eliminate about 68.09\%'s average risk, and the proper size of loan portfolio for sub-branches will be 15 which can eliminate about 74.79\%'s risk. The target with maximum RAROC of the comprehensive profit on loan can carry out for commercial banks under acceptable risk.

\section{ACKNOWLEDGEMENT}

The authors would like to thank the referees and editor for their helpful comments and suggestions that significantly improved the paper. And this research was supported by Youth Project of National Social Science Fund of China (12CGL020); Fund of Ministry of Education of Humanities and Social Sciences (12YJA790110)

\section{REFERENCES}

[1] Haas, R. D., Ferreira, D. \& Taci A. 2010. What determines the composition of bank's loan portfolios? Evidence from transition countries. Journal of Banking and Finance (34): 388-398.

[2] Wu, S. N. \& Wei, S. Y. 1998. An empirical study of the relationship between the scale of the investment combination on Shanghai stock market and its risk. The Economic Research Journal (4): 21-29.

[3] Yang, J. P. \& Zhang, L. J. 2005. A further study of the relationship between size of portfolios and risk diversification in Shanghai stock market. Systems Engineering Theory and Practice (10): 21-28.

[4] Chen, J., Hu, W.W. \& Li, Z. 2008. Diversification effects of idiosyncratic risk of portfolio sizes in Chinese stock market. Soft Science 22 (2): 39-42.

[5] Willenbrock, S. 2011. Diversification return, portfolio rebalancing, and the commodity puzzle. Financial Analysts Journal (67): 42-49. 